\title{
Hypothyroidism and Nonalcoholic Fatty Liver Disease: Pathophysiological Associations and Therapeutic Implications
}

\author{
Tomislav Kizivat $\# 1,2$, Ivana Maric ${ }^{1,2}$, Dunja Mudri, ${ }^{1,2}$, Ines Bilic Curcic ${ }^{\# 1,2}$, \\ Dragan Primorac $1,3,4,5,6,7,8$ and Martina Smolic*1,8 \\ ${ }^{1}$ University of Osijek, Faculty of Medicine, Osijek, Croatia; ${ }^{2}$ University Hospital Osijek, Osijek, Croatia; ${ }^{3}$ St Catherine Specialty \\ Hospital, Zagreb \& Zabok, Croatia; ${ }^{4}$ University of Split School of Medicine, Split, Croatia; ${ }^{5}$ Eberly College of Science, State College, \\ Penn State University, PA, USA; ${ }^{6}$ The Henry C Lee College of Criminal Justice \& Forensic Sciences, University of New Haven, West \\ Haven, CT, USA; ${ }^{7}$ University of Rijeka School of Medicine, Rijeka, Croatia; ${ }^{8}$ University of Osijek Faculty of Dental Medicine \& \\ Health, Osijek, Croatia
}

\begin{abstract}
Nonalcoholic fatty liver disease (NAFLD) is a complex clinical entity which can be secondary to many other diseases including hypothyroidism, characterized by lowering of thyroid hormones and increased thyroid stimulating hormone (TSH). A lot of emerging data published recently advocates the hypothesis that hypothyroid induced NAFLD could be a separate clinical entity, even suggesting possible treatment options for NAFLD involving substitution therapy for hypothyroidism along with lifestyle modifications. In addition, a whole new field of research is focused on thyromimetics in NAFLD/NASH treatment, currently in phase 3 clinical trials. In this critical review we summarized epidemiological and pathophysiological evidence linking these two clinical entities and described specific treatment options with the accent on promising new agents in NAFLD treatment, specifically thyroid hormone receptor (THR) agonist and its metabolites.

Citation of this article: Kizivat T, Maric I, Mudri D, Curcic IB, Primorac D, Smolic M. Hypothyroidism and nonalcoholic fatty liver disease: Pathophysiological associations and therapeutic implications. J Clin Transl Hepatol 2020;8(3):347-353. doi: 10.14218/JCTH.2020.00027.
\end{abstract}

\section{Introduction}

Interest in nonalcoholic fatty liver disease (NAFLD) has been growing rapidly in research and in clinical practice over the last 25 years. Much effort and extensive research in the field have yielded important information on risk factors for devel-

Keywords: NAFLD; MAFLD; Hypothyroidism; Metabolic syndrome; Thyromimetics. Abbreviations: HMG-CoA, 3-hydroxy-3-methyl-glutaryl coenzyme A; LDL cholesterol, low-density lipoprotein cholesterol; NAFLD, nonalcoholic fatty liver disease; $\mathrm{NASH}$, nonalcoholic steatohepatitis; ROS, reactive oxygen species; SREBP-1c, sterol regulatory element-binding transcription factor 1c; T1AM, 3-iodothyronamine; T2, 3,5-diiodothyronine; TG, triglyceride; THR, thyroid hormone receptor; TNF- $\alpha_{\text {, }}$ tumor necrosis factor- $\alpha$; TSH, thyroid stimulating hormone.

Received: 7 April 2020; Revised: 5 June 2020; Accepted: 28 June 2020

${ }^{\#}$ Both authors contributed equally to this manuscript.

*Correspondence to: Martina Smolic, University of Osijek, Faculty of Medicine, Department of Pharmacology; Faculty of Dental Medicine and Health, Department of Pharmacology and Biochemistry, J. Huttlera 4, 31000 Osijek, Croatia. Tel: +385-31-512-800, Fax: +385-31-512-833, E-mail: martina.smolic@mefos.hr opment and progression of the disease ${ }^{1}$ hepatic and extrahepatic complications ${ }^{2}$ and on treatment. ${ }^{3}$ In the last 20 years, NAFLD has become one of the most common liver diseases in the world, encompassing almost $25 \%$ of the world's population and including children. ${ }^{4}$

Metabolic syndrome is defined as a cluster of risk factors, including visceral adiposity which increases insulin resistance and predisposes to type 2 diabetes (decreased glucose tolerance), dyslipidemia and hypertension. Each of these factors predicts development of all of the others, thereby clustering them in a metabolic syndrome disorder over time. ${ }^{5}$ Hormonal disbalance, including of sex hormones, growth hormones and thyroid hormones, can also be a predisposing factor for development of metabolic syndrome. ${ }^{6-8}$ NAFLD as a primary disease can follow, coexist or precede metabolic syndrome, but it can also be secondary to other causes. ${ }^{9}$

Some of the secondary causes of NAFLD include viral infections, nutrition, drugs, surgery and some endocrine diseases like primary hypothyroidism, hypogonadism, growth hormone deficiency and polycystic ovary syndrome. ${ }^{9}$ Recently, NAFLD induced by hypothyroidism has been described as a distinct disease entity, due to its strong epidemiological connection and unique pathophysiology; as such, it could serve as a model for identification of new therapeutic options for some cases of primary NAFLD. ${ }^{10,11}$ An additional issue is subclinical hypothyroidism, since it has been reported that one in six patients with NAFLD have concomitant subclinical hypothyroidism, presumably related to carbohydrate metabolism disorders. ${ }^{12}$ Surprisingly, Lee and colleagues ${ }^{13}$ reported that in Korean population with hepatic steatosis index of 36 or higher, subclinical hypothyroidism was related to a high risk of NAFLD in males but not in females.

In this critical review, we describe and summarize evidence on epidemiological and pathophysiological associations as well as treatment options for hypothyroid-induced NAFLD. It is important to note that in clinical practice, this association is often not considered by endocrinologists, and moreover gastroenterologists often dismiss underlying thyroid hormone disbalance, leading to NAFLD. Thus, it is necessary to sensitize all specialties involved, in order to adequately address this issue. 


\section{Epidemiological background}

Prevalence of primary hypothyroidism is between $0.3 \%$ and $3.7 \%$ in the general population of the USA and 0.2 and $5.3 \%$ of the European general population. It is defined by biochemical increase of thyroid-stimulating hormone (TSH) and lowering of the thyroid hormones thyroxine and triiodothyronine, as clinical or overt hypothyroidism, and as subclinical hypothyroidism if only TSH is increased and thyroid hormones are in reference interval. ${ }^{14}$

Not all observational studies and meta-analyses show connection between hypothyroidism and NAFLD (Table 1). For instance, a recent meta-analysis (published in 2018, with a total of 12 cross-sectional and 3 longitudinal studies that had enrolled 44,140 subjects) has shown that overt hypothyroidism was associated with an increased risk of NAFLD; however, subclinical hypothyroidism was not independently associated with risk of NAFLD. ${ }^{15}$ Another metaanalysis published in 2018 also, and including 61,548 patients from 26 studies showed that patients with NAFLD had significantly higher TSH levels than those without NAFLD, independent of thyroid hormones and thereby showing that unclassified hypothyroidism was associated with an increased risk of NAFLD. ${ }^{16}$ A cross-sectional study of 425 biopsy-proven NAFLD patients showed that nonalcoholic steatohepatitis (NASH) and advanced fibrosis were independently related to low thyroid function, with risk proportional to the increase of $\mathrm{TSH} .{ }^{17}$ These findings were confirmed in several other studies. ${ }^{18,19}$ In addition, some specific features of hypothyroidism and NAFLD single it out as a distinct disease entity, especially the reports of the development of hepatocellular carcinoma in patients with hypothyroidism. ${ }^{20,21}$

On the other hand, there are some studies showing the opposite (Table 1 ). Escude et al. ${ }^{22}$ in a recent retrospective study involving 10116 subjects showed no significant connections concerning hypothyroidism and NAFLD with respect to controls. In a longitudinal cohort study in South Korea including 18500 subjects with hypothyroidism, both clinical and subclinical, did not find any significant correlation with increased risk of NAFLD. ${ }^{23}$

These conflicting results could be in part explained by differences in study design, specific characteristics of investigated populations, differences in definition of hypothyroidism (clinical and subclinical) and NAFLD, and variations in diagnosis of NAFLD. However, if all the above-mentioned studies are taken together, there are indications that hypothyroidism, both clinical and subclinical, could be associated to NAFLD; although, a conclusive proof is still lacking.

\section{Pathophysiological background}

NAFLD is a chronic liver disease with the pathohistological manifestations ranging from steatosis to $\mathrm{NASH}$, with an increased risk of progression to cirrhosis and ultimately even to hepatocellular carcinoma. ${ }^{24,25}$ The pathogenesis of NAFLD is complex and certainly multifactorial, including genetic predisposition, metabolic and environmental factors. ${ }^{26}$ According to the results of previous studies, the key points in the pathogenesis of hypothyroidism-induced NAFLD are metabolic changes, direct action of TSH on the hepatocytes and oxidative stress are summarized in Fig. 1. 10,27

Obesity, dyslipidemia and insulin resistance, the main features of metabolic syndrome which are also common in patients with overt and subclinical hypothyroidism are strongly associated with NAFLD ${ }^{9,27,28}$ (also recently known as metabolic associated fatty liver disease and referred as MAFLD) Moreover, overt and subclinical hypothyroidism is considered to be an independent risk factor for NAFLD. ${ }^{18,29}$ The rising prevalence of obesity during the past decades could be related to the development of NAFLD. ${ }^{30}$ According to studies, there is an increased prevalence of hypothyroidism in the overweight population compared to the general population. ${ }^{31}$ Furthermore, the incidence of NAFLD directly correlates with body mass index. ${ }^{32}$

Thyroid hormones have a significant role in hepatic lipid metabolism; acting through the thyroid hormone $\beta$ receptors, they can lead to hepatic fat accumulation and stimulate hepatic lipogenesis. ${ }^{33}$ Also, thyroid hormones modify lipid accumulation in the liver, affecting leptin and adiponectin; cytokines that also have significance in the pathogenesis of hepatic steatosis. ${ }^{19,34}$ Leptin stimulates beta-oxidation and suppresses lipogenesis, ${ }^{35}$ while an inverse correlation has been found in many studies to exist between adiponectin, triglyceride (TG), and low-density lipoprotein (LDL)-cholesterol. ${ }^{36-38}$ Previous studies have shown that not only thyroid hormones but also thyroid hormone derivatives provide an important contribution to hepatic lipid metabolism. According to results in in vitro studies, thyroid hormone derivative 3,5-diiodo-L-thyronine (T2) lowers excess fat in cultured hepatocytes. ${ }^{39,40}$

The important effect of thyroid hormone derivatives, such as reduction of lipid accumulation and stimulation of lipid oxidation, is also supported by the results of in vivo studies. ${ }^{41,42}$ In the studies of the direct effects of thyroid hormone on hepatic lipid metabolism, it has been found that the intrahepatic thyroid hormone concentration could be decreased in those patients with NAFLD. ${ }^{43,44}$ In addition, hypothyroidism is associated with impaired glucose and insulin metabolism, a major risk factor for NAFLD. ${ }^{45}$ Insulin resistance leads to decreased responsiveness of glucose uptake in muscle and fat tissues, and to insulin, further affecting the lipid profile. ${ }^{46-48}$ It is considered that leptin and certain adipocytokines [e.g., tumor necrosis factor (TNF)- $\alpha$ and interleukin-1] play a significant role in hypothyroidism and insulin resistance, affecting the development and progression of NAFLD. ${ }^{10,27,43}$

Mechanisms linking NASH and hypothyroidism are relatively clear, but whether they can be applied to subclinical hypothyroidism remains an open question. A recently published study investigating miRNA alterations and proteome profiles in a subclinical hypothyroidism mouse model identified several different miRNA-protein regulatory modules potentially associated with hepatic lipid metabolism, contributing to the growing body of evidence connecting thyroid hormones and NAFLD. 49

Although, seemingly, the main reason for steatohepatitis in patients with hypothyroidism is a decrease in thyroid hormone levels, elevated $\mathrm{TSH}$, regardless of thyroid hormone levels, could also affect the development of NAFLD. ${ }^{43}$ Through binding to the TSH receptor on the cell membrane of hepatocytes, elevated serum TSH causes liver TG accumulation via hepatic sterol regulatory elementbinding transcription factor 1 (SREBP-1c) up-regulation, subsequently causing steatosis. ${ }^{10,27,50}$ Furthermore, TSH stimulates hepatic gluconeogenesis and causes hypercholesterolemia by decreasing hepatic 3-hydroxy-3methyl-glutaryl coenzyme A (commonly referred to as 


\begin{tabular}{|c|c|c|c|c|}
\hline Reference & Study design & $\begin{array}{l}\text { Method for hypothyroidism } \\
\text { diagnosis }\end{array}$ & $\begin{array}{l}\text { Method for } \\
\text { NAFLD/HCC } \\
\text { diagnosis }\end{array}$ & Main results \\
\hline 15 & $\begin{array}{l}\text { Meta-analysis of } 12 \text { cross- } \\
\text { sectional and } 3 \text { longitudinal } \\
\text { studies with } 44,140 \text { included } \\
\text { subjects (adults, children } \\
\text { and adolescents) }\end{array}$ & $\begin{array}{l}\text { Previous history of } \\
\text { hypothyroidism on } \\
\text { levothyroxine replacement } \\
\text { therapy or found abnormal } \\
\text { thyroid function tests }\end{array}$ & $\begin{array}{l}\text { Imaging } \\
\text { techniques } \\
\text { (mainly } \\
\text { ultrasound, } \\
\text { computed } \\
\text { tomography, or } \\
\text { liver biopsy }\end{array}$ & $\begin{array}{l}\text { Hypothyroidism is } \\
\text { significantly associated } \\
\text { with an increased risk of } \\
\text { NAFLD and severity of the } \\
\text { disease }\end{array}$ \\
\hline 16 & $\begin{array}{l}\text { Systematic review and } \\
\text { meta-analysis included } 26 \\
\text { studies with } 61,548 \text { subjects } \\
\text { ( } 60,319 \text { adults and } 1229 \\
\text { children and adolescents) }\end{array}$ & $\begin{array}{l}\text { Abnormal thyroid function } \\
\text { parameters, } \\
\text { hypothyroidism on } \\
\text { replacement levothyroxine } \\
\text { therapy }\end{array}$ & $\begin{array}{l}\text { Ultrasound, liver } \\
\text { biopsy, FLI or } \\
\text { MRS }\end{array}$ & $\begin{array}{l}\text { Elevated TSH may be a risk } \\
\text { factor for the development } \\
\text { of NAFLD/NASH, } \\
\text { independent of thyroid } \\
\text { hormones status }\end{array}$ \\
\hline 17 & $\begin{array}{l}\text { Cross-sectional study with } \\
425 \text { subjects }>18 \text { years }\end{array}$ & $\begin{array}{l}\text { Subclinical hypothyroidism } \\
\text { defined as TSH level over } \\
4.5 \text { mIU/L, with a normal T4 } \\
\text { level, low-normal thyroid } \\
\text { function as TSH level 2.5- } \\
4.5 \text { mIU/L and normal FT4 } \\
\text { level }\end{array}$ & $\begin{array}{l}\text { Ultrasound, } \\
\text { unexplained high } \\
\text { levels of ALT or } \\
\text { liver biopsy }\end{array}$ & $\begin{array}{l}\text { A strong relationship } \\
\text { between subclinical } \\
\text { hypothyroidism and NASH } \\
\text { with higher prevalence of } \\
\text { NASH in these subjects }\end{array}$ \\
\hline 18 & $\begin{array}{l}\text { Prospective, population- } \\
\text { based cohort study with } \\
9419 \text { subjects }\end{array}$ & $\begin{array}{l}\text { Abnormal thyroid function } \\
\text { test (TSH, T4 and TPOAb } \\
\text { measurement) }\end{array}$ & $\begin{array}{l}\text { Ultrasound and } \\
\text { FLI } \\
\text { measurements }\end{array}$ & $\begin{array}{l}\text { Hypothyroidism was } \\
\text { associated with a higher } \\
\text { risk of NAFLD development } \\
\text { in contrast to euthyroid }\end{array}$ \\
\hline 19 & $\begin{array}{l}\text { Systematic review of } 11 \\
\text { clinical studies with } 13,354 \\
\text { adults (>18 years) }\end{array}$ & $\begin{array}{l}\text { Thyroid function tests or } \\
\text { history of hypothyroidism } \\
\text { on levothyroxine } \\
\text { replacement therapy }\end{array}$ & $\begin{array}{l}\text { Liver ultrasound } \\
\text { or liver biopsy }\end{array}$ & Inconsistent results \\
\hline 20 & $\begin{array}{l}\text { Case-control study with } 160 \\
\text { subjects }\end{array}$ & $\begin{array}{l}\text { Hypothyroidism defined as } \\
\text { TSH }>5 \text { mIU/L, history of } \\
\text { hypothyroidism }\end{array}$ & $\begin{array}{l}\text { Histopathology } \\
\text { or clinical and } \\
\text { imaging criteria }\end{array}$ & $\begin{array}{l}\text { Hypothyroidism is } \\
\text { significantly higher } \\
\text { prevalent in subjects with } \\
\text { hepatocellular carcinoma of } \\
\text { unknown etiology } \\
\text { compared to controls with } \\
\text { viral or alcoholic liver } \\
\text { disease }\end{array}$ \\
\hline 21 & $\begin{array}{l}\text { Case-control study with } 420 \\
\text { subjects with hepatocellular } \\
\text { carcinoma and } 1104 \text { healthy } \\
\text { controls }\end{array}$ & $\begin{array}{l}\text { History of hypothyroidism } \\
\text { established during personal } \\
\text { interviews }\end{array}$ & $\begin{array}{l}\text { pathologically } \\
\text { confirmed }\end{array}$ & $\begin{array}{l}\text { Long-term hypothyroidism } \\
\text { is significantly associated } \\
\text { with hepatocellular } \\
\text { carcinoma only among } \\
\text { women }\end{array}$ \\
\hline 22 & $\begin{array}{l}\text { Cross-sectional, } \\
\text { retrospective population } \\
\text { study with } 10,116 \text { subjects } \\
\geq 45 \text { years }\end{array}$ & $\begin{array}{l}\text { Subclinical hypothyroidism } \\
\text { as TSH }>4,94 \text { UI/mL and } \\
\text { normal T4; overt } \\
\text { hypothyroidism as elevated } \\
\text { TSH and decreased T4 }\end{array}$ & Ultrasound & $\begin{array}{l}\text { Hypothyroidism is not } \\
\text { associated with NAFLD }\end{array}$ \\
\hline 23 & $\begin{array}{l}\text { Retrospective cohort study } \\
\text { with } 18,544 \text { Korean subjects } \\
\text { aged } 20-65 \text { years }\end{array}$ & $\begin{array}{l}\text { Subclinical hypothyroidism, } \\
\text { defined as TSH }>4.2 \mathrm{mIU} / \mathrm{L} \text {, } \\
\text { normal FT4 and overt } \\
\text { hypothyroidism as TSH } \\
>4.2 \mathrm{mIU} / \mathrm{L}, \mathrm{FT} 4<0.97 \mathrm{ng} / \\
\text { dL }\end{array}$ & Ultrasound & $\begin{array}{l}\text { No association between } \\
\text { subclinical or overt } \\
\text { hypothyroidism and } \\
\text { increased incidence of } \\
\text { NAFLD }\end{array}$ \\
\hline
\end{tabular}

Abbreviations: ALT, alanine transaminase, FLI, fatty liver index; FT4, free thyroxine; HCC, hepatocellular carcinoma; MRS, magnetic resonance spectroscopy; NAFLD, nonalcoholic fatty liver disease; NASH, nonalcoholic steatohepatitis; T4, thyroxine; TPOAb, thyroid peroxidase antibody; TSH, thyroid stimulating hormone. 
Kizivat T. et al: Hypothyroidism and NAFLD

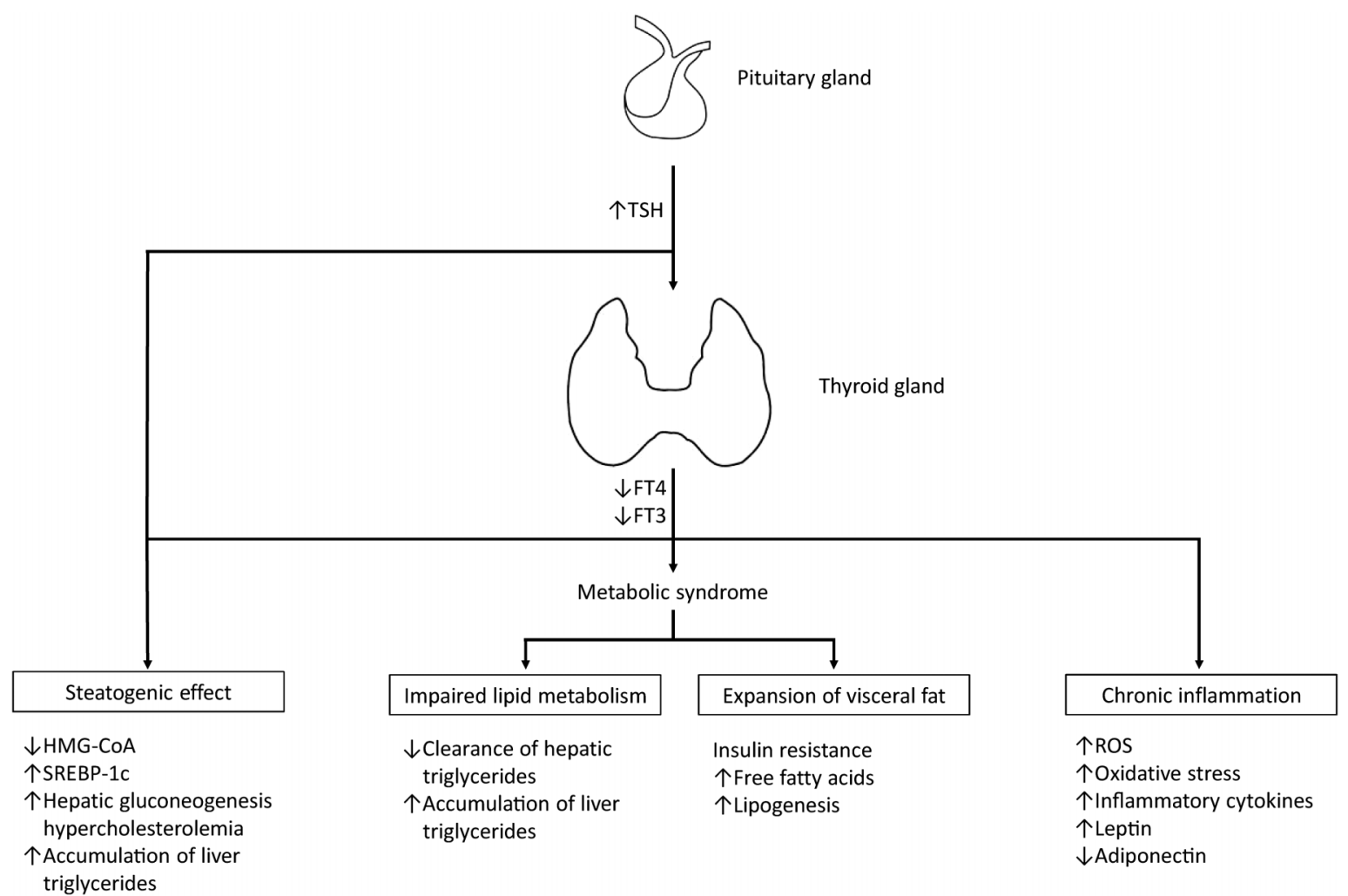

Fig. 1. Possible pathophysiological mechanisms leading to NAFLD in hypothyroidism. ${ }^{10} \uparrow$ indicates up-regulation or increased concentrations, $\downarrow$ indicates downregulation.

Abbreviations: FT3, free triiodothyronine; FT4, free thyroxine; ROS, reactive oxygen species; TSH, thyroid stimulating hormone.

HMG-CoA) reductase phosphorylation, ultimately leading to development and progression of NAFLD..$^{51-53}$

One of the potential pathophysiological mechanisms of hypothyroidism-induced NAFLD is oxidative stress. Hepatocytes' mitochondria play a key role in the fatty acid metabolism by $\beta$-oxidation of free fatty acids, electron transfer and production of adenosine triphosphate, and reactive oxygen species (referred to as ROS). ${ }^{54}$ In NAFLD, impaired mitochondrial function initiates an increase of nonmetabolized fatty acids in the cytosol as a result of the blockade of fatty acid $\beta$-oxidation. Consequently, increased production of ROS occurs. ${ }^{55}$ An increase in ROS production leads to hepatocyte damage and inflammation. ${ }^{56}$ Since patients with hypothyroidism have elevated markers of oxidative stress, oxidative stress in this patients could be the cause of cellular damage in liver tissue by reducing $\beta$-oxidation of fatty acids and increasing peroxidation of lipids. ${ }^{10,27}$

On the other hand, liver plays a significant role in metabolism of thyroid hormones and liver disfunction could cause variations in the bioavailability of such. ${ }^{57}$ Thyroid hormone metabolism is regulated by iodothyronine seleno-deiodinase enzymes. Two of these enzymes are expressed in liver: type 1 , which converts thyroxine to triiodothyronine, thus activating it; and type 3 , which prevents activation of thyroxine by converting it to an inactive metabolite reverse triiodothyronine. ${ }^{58}$ Liver also extracts $5-10 \%$ of thyroxine in plasma during a single passage, and it synthesizes major transport proteins for thyroid hormones, including thyroxine-binding globulin, transtyrethin and albumin, which provide a pool for rapid exchange of circulating thyroid hormones. ${ }^{57}$ However, these changes in liver and thyroid metabolism in NAFLD would not have a significant influence on thyroid function

\section{Treatment implications}

Since hypothyroidism is often associated with clinical features of metabolic syndrome, ${ }^{10}$ while NAFLD and metabolic syndrome are connected bidirectionally, ${ }^{5}$ special attention should be given to patients with NAFLD and hypothyroidism, specifically in obese or overweight individuals. ${ }^{59}$ Although there are no specific guidelines recommending treatment of these diseases combined, epidemiological and pathophysiological background support the rationality that both diseases should be taken into consideration when choosing the right therapeutic modality.

Fortunately, therapy for hypothyroidism is well known and easy to apply. Replacement therapy with levothyroxine can significantly decrease serum lipids and decrease body mass, ${ }^{14}$ thus improving clinical features of metabolic syndrome. It has been reported that implementation of levothyroxine replacement therapy in patients with subclinical hypothyroidism and dyslipidemia can decrease prevalence of NAFLD. Results supporting this were more convincing in severe subclinical hypothyroidism in comparison to a mild form. ${ }^{60}$ Improvement in intrahepatic lipid deposits using low doses of levothyroxine in euthyroid male patients with NAFLD and type 2 diabetes mellitus was also demonstrated. ${ }^{61}$ 
A major issue in NAFLD patients is progression to NASH, and the development of any therapeutic options that could potentially address this problem would be welcome. It seems that liver lipotoxicity can be one of the main contributors leading to NASH development and possibly to its progression. ${ }^{62}$ One of the potential agents preventing liver damage is thyroid hormone receptor (THR) agonists since thyroid hormone potentiates TG degradation, decreases fatty acid synthesis and stimulates hepatocyte regeneration. ${ }^{43,63,64}$

However, induced hyperthyroidism causes many problems which could be avoided with selective THR- $\beta$ agonists. THRs have two main subtypes (THR- $\alpha$ and THR- $\beta$ ), with heart rate being primarily controlled by THR- $\alpha$ while stimulation of THR$\beta$ decreases LDL, TG, hepatic steatosis and body weight. ${ }^{62}$ Initially, selective THR- $\beta$ agonists were developed for treatment of hypercholesterolemia, due to their capability of lowering LDL cholesterol. ${ }^{65-67}$ Regardless of successful phase 2 trials, further investigations were terminated due to significant increase in liver enzymes with one of the agents in question, eprotirome. ${ }^{68}$ Nonetheless, efforts were taken to investigate a new generation of THR- $\beta$ agonist in NAFLD treatment, irrespective of thyroid function. ${ }^{69,70}$ In a phase 2 clinical trial investigating such, the drug resmetirom (MGL-3196) was applied to patients with biopsy-confirmed NASH and a significant decrease in liver fat after 12 and after 36 weeks of the treatment was achieved. ${ }^{71}$ In March 2019, initiation of a phase 3 trial testing the use of resmetirom in patients with fibrotic NASH was announced by Madrigal Pharmaceuticals. A phase 2 clinical trial of another selective thyromimetic, VK2809, demonstrated similar results. ${ }^{72}$

Other thyroid hormone metabolites that could improve NAFLD/NASH treatment are T2 and 3-iodothyronamine (referred to as T1AM). A study performed in rats demonstrated that exogenous T2 could decrease liver fat, TGs and LDL cholesterol; ${ }^{73}$ however, small human studies including up to 40 patients with metabolic syndrome treated with $\mathrm{T} 2$ showed no effect on lipid profile and insulin resistance. ${ }^{74}$ The other compound in question is T1AM, a biogenic amine affecting lipid and glucose metabolism at relatively low doses and so far tested in animal models only; although, it has shown beneficial effects on cholesterol and TG levels. ${ }^{75,76}$

So far, use of selective THR- $\beta$ agonists has been investigated in euthyroid patients. Although they are selective agonists, beta receptors are also found in the pituitary gland and stimulation of TSH secretion is possible. The questions arise whether hypothyroid patients should be treated with these drugs at all and, if so, how to monitor adequate substitution and adjust dosage of substitution therapy. In order to determine whether potential benefits outweigh the risks, further research is necessary.

Last but not the least, the role of lifestyle modifications should not be ignored in treatment of patients with NAFLD, hypothyroidism and metabolic syndrome; it is important to note, as well, that in combination with levothyroxine replacement therapy, significant improvement of metabolic components can be achieved. ${ }^{9}$ There are also still no published studies investigating currently used therapies recommended in NASH, such as antioxidative agents (vitamin E) and insulin sensitizers (pioglitazone) ${ }^{77}$ for this particular subset of patients.

\section{Research questions}

The major issue is progression of NAFLD from simple steatosis to end-stage liver disease, both in other diseases and in hypothyroidism. Thus, further studies are needed that specifically compare the natural course of NAFLD secondary to hypothyroidism and primary NAFLD, which would clarify whether, for example, patients with hypothyroidism, despite substitution therapy with levothyroxine, have an accelerated progression of liver fibrosis.

Regarding treatment of NAFLD and hypothyroidism, some improvements have been made by levothyroxine replacement therapy in addition to lifestyle changes. However, a major breakthrough in NAFLD/NASH treatment could be accomplished with selective THR- $\beta$ agonists, so far investigated in euthyroid patients exclusively. Still, application of these drugs in hypothyroid patients remains questionable and pending the results of future studies. Presently, there are no studies available investigating the effect of insulin sensitizers and antioxidants in patients with NAFLD and hypothyroidism; thus, it would be interesting to explore these therapy options in in vivo and in vitro settings.

\section{Conclusions}

NAFLD is characterized by intrahepatic depositions of fat, which causes an intricate web of histological, metabolic and extrahepatic ramifications. Its pathogenesis is still not fully understood, and therefore treatment is still not very successful, while its global epidemiological, clinical and economic burdens are rapidly increasing.

The role of thyroid hormones and their derivatives as well as TSH levels and oxidative stress in lipid and glucose metabolism is well substantiated. Based on the available evidence, causative association of NAFLD and hypothyroidism, both clinical and subclinical is highly conceivable; although, both hypothyroidism and NAFLD share standard features, such as obesity, metabolic syndrome, insulin resistance, and dyslipidemia. Therefore, more data are required in order to assess the causal relationship between hypothyroidism and NAFLD.

\section{Funding}

This research was funded by grant from Croatian Ministry of Science and Education dedicated to multi-year institutional funding of scientific activity at the J.J. Strossmayer University of Osijek, Osijek, Croatia-grant's number: IP-2019-MEFOS10 (to M.S.).

\section{Conflict of interest}

The authors have no conflict of interests related to this publication.

\section{Author contributions}

Conceived of and designed the article, and critically revised the manuscript (IBC, MS), obtained funding, and provided administrative, technical and material support (IBC, MS), performed literature searches and wrote the manuscript (TK, IM, DM), updated the text of the manuscript (IBC, TK), figure drawing (TK), critical revision of the manuscript for important intellectual content (DP). 


\section{References}

[1] Valenti L, Romeo S. Destined to develop NAFLD? The predictors of fatty liver from birth to adulthood. J Hepatol 2016;65:668-670. doi: 10.1016/j.jhep. 2016.06.010.

[2] Singh S, Allen AM, Wang Z, Prokop L], Murad MH, Loomba R. Fibrosis progression in nonalcoholic fatty liver vs nonalcoholic steatohepatitis: a systematic review and meta-analysis of paired-biopsy studies. Clin Gastroenterol Hepatol 2015:13:643-554.e1-9, doi: 10.1016/j.cgh.2014.04.014.

[3] Italian Association for the Study of the Liver (AISF). AISF position paper on nonalcoholic fatty liver disease (NAFLD): Updates and future directions. Dig Liver Dis 2017;49:471-483. doi: 10.1016/j.dld.2017.01.147.

[4] Younossi Z, Tacke F, Arrese M, Chander Sharma B, Mostafa I, Bugianesi E, et al. Global perspectives on nonalcoholic fatty liver disease and nonalcoholic steatohepatitis. Hepatology 2019;69:2672-2682. doi: 10.1002/hep.30251.

[5] Lonardo A, Ballestri S, Marchesini G, Angulo P, Loria P. Nonalcoholic fatty liver disease: a precursor of the metabolic syndrome. Dig Liver Dis 2015;47:181190. doi: $10.1016 /$ j.dld.2014.09.020.

[6] Dwyer AA, Quinton R. The metabolic syndrome in central hypogonadotrophic hypogonadism. Front Horm Res 2018;49:156-169. doi: 10. $1159 / 000485998$.

[7] Iwen KA, Oelkrug R, Kalscheuer H, Brabant G. Metabolic syndrome in thyroid disease. Front Horm Res 2018;49:48-66. doi: 10.1159/000485996.

[8] Pasquali R. Metabolic syndrome in polycystic ovary syndrome. Front Horm Res 2018;49:114-130. doi: 10.1159/000485995.

[9] Lonardo A, Mantovani A, Lugari S, Targher G. NAFLD in some common endocrine diseases: Prevalence, pathophysiology, and principles of diagnosis and management. Int J Mol Sci 2019;20:2841. doi: 10.3390/ijms20112841.

[10] Lonardo A, Ballestri S, Mantovani A, Nascimbeni F, Lugari S, Targher G. Pathogenesis of hypothyroidism-induced NAFLD: Evidence for a distinct disease entity? Dig Liver Dis 2019;51:462-470. doi: 10.1016/j.dld.2018. 12.014 .

[11] Manka P, Bechmann L, Best J, Sydor S, Claridge LC, Coombes JD, et al. Low free triiodothyronine is associated with advanced fibrosis in patients at high risk for nonalcoholic steatohepatitis. Dig Dis Sci 2019;64:2351-2358. doi: 10.1007/s10620-019-05687-3.

[12] Feisa SV, Chopei IV. Subclinical hypothyroidism in patients with non-alcoholic fatty liver disease at the background of carbohydrate metabolism disorders. Wiad Lek 2018;71:261-264.

[13] Lee J, Ha J, Jo K, Lim DJ, Lee JM, Chang SA, et al. Male-specific association between subclinical hypothyroidism and the risk of non-alcoholic fatty liver disease estimated by hepatic steatosis index: Korea National Health and Nutrition Examination Survey 2013 to 2015. Sci Rep 2018;8:15145. doi: 10.1038/s41598-018-32245-0.

[14] Chaker L, Bianco AC, Jonklaas J, Peeters RP. Hypothyroidism. Lancet 2017; 390:1550-1562. doi: 10.1016/S0140-6736(17)30703-1.

[15] Mantovani A, Nascimbeni F, Lonardo A, Zoppini G, Bonora E, Mantzoros CS et al. Association between primary hypothyroidism and nonalcoholic fatty liver disease: A systematic review and meta-analysis. Thyroid 2018;28: 1270-1284. doi: 10.1089/thy.2018.0257.

[16] Guo Z, Li M, Han B, Qi X. Association of non-alcoholic fatty liver disease with thyroid function: A systematic review and meta-analysis. Dig Liver Dis 2018; 50:1153-1162. doi: 10.1016/j.dld.2018.08.012.

[17] Kim D, Kim W, Joo SK, Bae JM, Kim JH, Ahmed A. Subclinical hypothyroidism and low-normal thyroid function are associated with nonalcoholic steatohepatitis and fibrosis. Clin Gastroenterol Hepatol 2018;16:123-131.e1. doi: 10.1016/j.cgh.2017.08.014.

[18] Bano A, Chaker L, Plompen EP, Hofman A, Dehghan A, Franco OH, et al. Thyroid function and the risk of nonalcoholic fatty liver disease: The rotterdam study. J Clin Endocrinol Metab 2016;101:3204-3211. doi: 10.1210/jc. 2016-1300.

[19] Eshraghian A, Hamidian Jahromi A. Non-alcoholic fatty liver disease and thyroid dysfunction: a systematic review. World J Gastroenterol 2014;20: 8102-8109. doi: 10.3748/wjg.v20.i25.8102.

[20] Reddy A, Dash C, Leerapun A, Mettler TA, Stadheim LM, Lazaridis KN, et al. Hypothyroidism: a possible risk factor for liver cancer in patients with no known underlying cause of liver disease. Clin Gastroenterol Hepatol 2007; 5:118-123. doi: 10.1016/j.cgh.2006.07.011.

[21] Hassan MM, Kaseb A, Li D, Patt YZ, Vauthey JN, Thomas MB, et al. Association between hypothyroidism and hepatocellular carcinoma: a case-contro study in the United States. Hepatology 2009;49:1563-1570. doi: 10. 1002/hep.22793.

[22] Martínez Escudé A, Pera G, Arteaga I, Expósito C, Rodríguez L, Torán P, et al. Relationship between hypothyroidism and non-alcoholic fatty liver disease in the Spanish population. Med Clin (Barc) 2020;154:1-6. doi: 10.1016/j. medcli.2019.03.018

[23] Lee KW, Bang KB, Rhee EJ, Kwon HJ, Lee MY, Cho YK. Impact of hypothyroidism on the development of non-alcoholic fatty liver disease: A 4-year retrospective cohort study. Clin Mol Hepatol 2015:21:372-378. doi: 10 . 3350/cmh.2015.21.4.372.

[24] Caligiuri A, Gentilini A, Marra F. Molecular pathogenesis of NASH. Int ] Mol Sci 2016;17:1575. doi: 10.3390/ijms17091575

[25] Pais R, Barritt AS 4th, Calmus Y, Scatton O, Runge T, Lebray P, et al. NAFLD and liver transplantation: Current burden and expected challenges. J Hepatol 2016;65:1245-1257. doi: 10.1016/j.jhep.2016.07.033.

[26] Lonardo A, Nascimbeni F, Maurantonio M, Marrazzo A, Rinaldi L, Adinolfi LE. Nonalcoholic fatty liver disease: Evolving paradigms. World J Gastroentero 2017;23:6571-6592. doi: 10.3748/wjg.v23.i36.6571.

[27] Lugari S, Mantovani A, Nascimbeni F, Lonardo A. Hypothyroidism and nonalcoholic fatty liver disease - a chance association? Horm Mol Biol Clin Investig 2018;41. doi: 10.1515/hmbci-2018-0047.

[28] Byrne CD, Targher G. NAFLD: a multisystem disease. ] Hepatol 2015;62: S47-S64. doi: 10.1016/j.jhep.2014.12.012.

[29] Chung GE, Kim D, Kim W, Yim JY, Park MJ, Kim Y], et al. Non-alcoholic fatty liver disease across the spectrum of hypothyroidism. J Hepatol 2012;57: 150-156. doi: 10.1016/j.jhep.2012.02.027.

[30] Rinella ME. Nonalcoholic fatty liver disease: a systematic review. JAMA 2015; 313:2263-2273. doi: 10.1001/jama.2015.5370.

[31] Raftopoulos Y, Gagné DJ, Papasavas P, Hayetian F, Maurer J, Bononi P, et al. Improvement of hypothyroidism after laparoscopic Roux-en-Y gastric bypass for morbid obesity. Obes Surg 2004;14:509-513. doi: 10. 1381/096089204323013514.

[32] Bonato V, St Louis M, Desai J, Gill JM, Welsh P, Waterworth D, et al. Body mass index and risk of nonalcoholic fatty liver disease: Two electronic health record prospective studies. J Clin Endocrinol Metab 2016;101:945-952. doi: $10.1210 /$ jc. $2015-3444$.

[33] Cordeiro A, Souza LL, Einicker-Lamas M, Pazos-Moura CC. Non-classic thyroid hormone signalling involved in hepatic lipid metabolism. J Endocrinol 2013;216:R47-R57. doi: 10.1530/JOE-12-0542.

[34] Turer AT, Scherer PE. Adiponectin: mechanistic insights and clinical implications. Diabetologia 2012;55:2319-2326. doi: 10.1007/s00125-012-2598

[35] Minokoshi Y, Kim YB, Peroni OD, Fryer LG, Müller C, Carling D, et al. Leptin stimulates fatty-acid oxidation by activating AMP-activated protein kinase. Nature 2002;415:339-343. doi: 10.1038/415339a.

[36] Finelli C, Tarantino G. What is the role of adiponectin in obesity related nonalcoholic fatty liver disease? World J Gastroenterol 2013;19:802-812. doi: 10.3748/wjg.v19.i6.802.

[37] Musso G, Gambino R, Biroli G, Carello M, Fagà E, Pacini G, et al. Hypoadiponectinemia predicts the severity of hepatic fibrosis and pancreatic Beta-cell dysfunction in nondiabetic nonobese patients with nonalcoholic steatohepatitis. Am J Gastroenterol 2005;100:2438-2446. doi: 10.1111/j.1572-0241. 2005.00297.x.

[38] Polyzos SA, Toulis KA, Goulis DG, Zavos C, Kountouras J. Serum total adiponectin in nonalcoholic fatty liver disease: a systematic review and metaanalysis. Metabolism 2011;60:313-326. doi: 10.1016/j.metabol.2010.09. 003.

[39] Grasselli E, Voci A, Canesi L, Goglia F, Ravera S, Panfoli I, et al. Non-receptormediated actions are responsible for the lipid-lowering effects of iodothyronines in FaO rat hepatoma cells. J Endocrinol 2011;210:59-69. doi: 10 1530/JOE-11-0074.

[40] Grasselli E, Voci A, Canesi L, De Matteis R, Goglia F, Cioffi F, et al. Direct effects of iodothyronines on excess fat storage in rat hepatocytes. J Hepatol 2011;54:1230-1236. doi: 10.1016/j.jhep.2010.09.027.

[41] Grasselli E, Voci A, Demori I, Canesi L, De Matteis R, Goglia F, et al. 3,5Diiodo-L-thyronine modulates the expression of genes of lipid metabolism in a rat model of fatty liver. J Endocrinol 2012;212:149-158. doi: 10 . 1530/JOE-11-0288.

[42] Senese R, Cioffi $F$, de Lange $P$, Leanza $C$, Iannucci LF, Silvestri $E$, et al. Both 3,5-diiodo-I-thyronine and 3,5,3'-triiodo-I-thyronine prevent short-term hepatic lipid accumulation via distinct mechanisms in rats being fed a highfat diet. Front Physiol 2017;8:706. doi: 10.3389/fphys.2017.00706.

[43] Sinha RA, Singh BK, Yen PM. Direct effects of thyroid hormones on hepatic lipid metabolism. Nat Rev Endocrinol 2018;14:259-269. doi: 10 1038/nrendo.2018.10.

[44] Sinha RA, Singh BK, Yen PM. Thyroid hormone regulation of hepatic lipid and carbohydrate metabolism. Trends Endocrinol Metab 2014;25:538-545. doi: 10.1016/j.tem.2014.07.001.

[45] Peppa M, Koliaki C, Nikolopoulos P, Raptis SA. Skeletal muscle insulin resistance in endocrine disease. J Biomed Biotechnol 2010;2010:527850. doi: 10 . $1155 / 2010 / 527850$.

[46] Dimitriadis G, Mitrou P, Lambadiari V, Boutati E, Maratou E, Panagiotakos DB, et al. Insulin action in adipose tissue and muscle in hypothyroidism. J Clin Endocrinol Metab 2006;91:4930-4937. doi: 10.1210/jc.2006-0478.

[47] Rochon C, Tauveron I, Dejax C, Benoit P, Capitan P, Fabricio A, et al. Response of glucose disposal to hyperinsulinaemia in human hypothyroidism and hyperthyroidism. Clin Sci (Lond) 2003;104:7-15. doi: 10 . $1042 / \operatorname{cs} 20020154$ 
[48] Bakker S], ter Maaten JC, Popp-Snijders C, Slaets JP, Heine RJ, Gans RO. The relationship between thyrotropin and low density lipoprotein cholesterol is modified by insulin sensitivity in healthy euthyroid subjects. J Clin Endocrinol Metab 2001;86:1206-1211. doi: 10.1210/jcem.86.3.7324.

[49] Zhang L, Wu K, Bo T, Zhou L, Gao L, Zhou X, et al. Integrated microRNA and proteome analysis reveal a regulatory module in hepatic lipid metabolism disorders in mice with subclinical hypothyroidism. Exp Ther Med 2020;19: 897-906. doi: 10.3892/etm.2019.8281.

[50] Yan F, Wang Q, Lu M, Chen W, Song Y, Jing F, et al. Thyrotropin increases hepatic triglyceride content through upregulation of SREBP-1c activity. J Hepatol 2014;61:1358-1364. doi: 10.1016/j.jhep.2014.06.037.

[51] Tian L, Song $Y$, Xing M, Zhang W, Ning G, Li X, et al. A novel role for thyroidstimulating hormone: up-regulation of hepatic 3-hydroxy-3-methyl-glutaryl-coenzyme A reductase expression through the cyclic adenosine monophosphate/protein kinase $\mathrm{A} / \mathrm{cyclic}$ adenosine monophosphate-responsive element binding protein pathway. Hepatology 2010;52:1401-1409. doi: 10.1002/hep.23800.

[52] Li Y, Wang L, Zhou L, Song Y, Ma S, Yu C, et al. Thyroid stimulating hormone increases hepatic gluconeogenesis via CRTC2. Mol Cell Endocrinol 2017;446: 70-80. doi: 10.1016/j.mce.2017.02.015.

[53] Zhang X, Song Y, Feng M, Zhou X, Lu Y, Gao L, et al. Thyroid-stimulating hormone decreases HMG-CoA reductase phosphorylation via AMP-activated protein kinase in the liver. J Lipid Res 2015;56:963-971. doi: 10.1194/jlr. M047654.

[54] Grattagliano I, de Bari O, Bernardo TC, Oliveira PJ, Wang DQ, Portincasa P. Role of mitochondria in nonalcoholic fatty liver disease-from origin to propagation. Clin Biochem 2012;45:610-618. doi: 10.1016/j.clinbiochem.2012. 03.024.

[55] Begriche K, Massart J, Robin MA, Bonnet F, Fromenty B. Mitochondrial adaptations and dysfunctions in nonalcoholic fatty liver disease. Hepatology 2013;58:1497-1507. doi: 10.1002/hep.26226.

[56] Satapati S, Kucejova B, Duarte JA, Fletcher JA, Reynolds L, Sunny NE, et al. Mitochondrial metabolism mediates oxidative stress and inflammation in fatty liver. J Clin Invest 2015;125:4447-4462. doi: 10.1172/JCI82204.

[57] Piantanida E, Ippolito $S$, Gallo D, Masiello E, Premoli $P$, Cusini $C$, et al. The interplay between thyroid and liver: implications for clinical practice. J Endocrinol Invest 2020;43:885-899. doi: 10.1007/s40618-020-01208-6.

[58] Luongo C, Dentice M, Salvatore D. Deiodinases and their intricate role in thyroid hormone homeostasis. Nat Rev Endocrinol 2019;15:479-488. doi: 10.1038/s41574-019-0218-2.

[59] Posadas-Romero C, Jorge-Galarza E, Posadas-Sánchez R, Acuña-Valerio J, Juárez-Rojas JG, Kimura-Hayama $\mathrm{E}$, et al. Fatty liver largely explains associations of subclinical hypothyroidism with insulin resistance, metabolic syndrome, and subclinical coronary atherosclerosis. Eur J Endocrinol 2014;171: 319-325. doi: 10.1530/EJE-14-0150.

[60] Liu L, Yu Y, Zhao M, Zheng D, Zhang X, Guan Q, et al. Benefits of levothyroxine replacement therapy on nonalcoholic fatty liver disease in subclinical hypothyroidism patients. Int J Endocrinol 2017;2017:5753039. doi: 10. $1155 / 2017 / 5753039$.

[61] Bruinstroop E, Dalan R, Cao Y, Bee YM, Chandran K, Cho LW, et al. Low-dose levothyroxine reduces intrahepatic lipid content in patients with type 2 diabetes mellitus and NAFLD. J Clin Endocrinol Metab 2018;103:2698-2706. doi: 10.1210/jc.2018-00475.

[62] Younossi Z. Emerging research on MGL-3196 for the treatment of nonalcoholic steatohepatitis. Gastroenterol Hepatol (N Y) 2019;15:317-319.
[63] Coppola M, Glinni D, Moreno M, Cioffi F, Silvestri E, Goglia F. Thyroid hormone analogues and derivatives: Actions in fatty liver. World J Hepatol 2014;6: 114-129. doi: 10.4254/wjh.v6.i3.114.

[64] Zucchi R. Thyroid hormone analogues: An update. Thyroid 2020. doi: 10. 1089/thy.2020.0071.

[65] Berkenstam A, Kristensen J, Mellström K, Carlsson B, Malm J, Rehnmark S, et al. The thyroid hormone mimetic compound KB2115 lowers plasma LDL cholesterol and stimulates bile acid synthesis without cardiac effects in humans. Proc Natl Acad Sci U S A 2008;105:663-667. doi: 10.1073/pnas. 0705286104.

[66] Taub R, Chiang E, Chabot-Blanchet M, Kelly MJ, Reeves RA, Guertin MC, et al. Lipid lowering in healthy volunteers treated with multiple doses of MGL3196 , a liver-targeted thyroid hormone receptor- $\beta$ agonist. Atherosclerosis 2013;230:373-380. doi: 10.1016/j.atherosclerosis.2013.07.056.

[67] Ladenson PW, Kristensen JD, Ridgway EC, Olsson AG, Carlsson B, Klein I, et al. Use of the thyroid hormone analogue eprotirome in statin-treated dyslipidemia. N Engl J Med 2010;362:906-916. doi: 10.1056/NEJMoa0905633.

[68] Sjouke B, Langslet G, Ceska R, Nicholls SJ, Nissen SE, Öhlander M, et al. Eprotirome in patients with familial hypercholesterolaemia (the AKKA trial): a randomised, double-blind, placebo-controlled phase 3 study. Lancet Diabetes Endocrinol 2014;2:455-463. doi: 10.1016/S2213-8587(14)70006-3.

[69] Jakobsson T, Vedin LL, Parini P. Potential role of thyroid receptor $\beta$ agonists in the treatment of hyperlipidemia. Drugs 2017;77:1613-1621. doi: 10 . 1007/s40265-017-0791-4.

[70] Alkhouri N. Thyromimetics as emerging therapeutic agents for nonalcoholic steatohepatitis: rationale for the development of resmetirom (MGL-3196). Expert Opin Investig Drugs 2020;29:99-101. doi: 10.1080/13543784. 2020.1708899.

[71] Harrison SA, Bashir MR, Guy CD, Zhou R, Moylan CA, Frias JP, et al. Resmetirom (MGL-3196) for the treatment of non-alcoholic steatohepatitis: a multicentre, randomised, double-blind, placebo-controlled, phase 2 trial. Lancet 2019;394:2012-2024. doi: 10.1016/S0140-6736(19)32517-6.

[72] Wong VW, Singal AK. Emerging medical therapies for non-alcoholic fatty liver disease and for alcoholic hepatitis. Transl Gastroenterol Hepatol 2019;4:53. doi: $10.21037 / \mathrm{tgh} .2019 .06 .06$

[73] Senese R, de Lange P, Petito G, Moreno M, Goglia F, Lanni A. 3,5-diiodothyronine: A novel thyroid hormone metabolite and potent modulator of energy metabolism. Front Endocrinol (Lausanne) 2018;9:427. doi: 10.3389/fendo. 2018.00427.

[74] van der Valk F, Hassing C, Visser M, Thakkar P, Mohanan A, Pathak K, et al. The effect of a diiodothyronine mimetic on insulin sensitivity in male cardiometabolic patients: a double-blind randomized controlled trial. PLoS One 2014;9:e86890. doi: 10.1371/journal.pone.0086890.

[75] Assadi-Porter FM, Reiland H, Sabatini M, Lorenzini L, Carnicelli V, Rogowski $\mathrm{M}$, et al. Metabolic reprogramming by 3 -iodothyronamine (T1AM): A new perspective to reverse obesity through co-regulation of sirtuin 4 and 6 expression. Int J Mol Sci 2018;19:1535. doi: 10.3390/ijms19051535.

[76] Selen Alpergin ES, Bolandnazar Z, Sabatini M, Rogowski M, Chiellini G, Zucchi $R$, et al. Metabolic profiling reveals reprogramming of lipid metabolic pathways in treatment of polycystic ovary syndrome with 3-iodothyronamine. Physiol Rep 2017;5:e13097. doi: 10.14814/phy2.13097.

[77] Polyzos SA, Kang ES, Boutari C, Rhee EJ, Mantzoros CS. Current and emerging pharmacological options for the treatment of nonalcoholic steatohepatitis. Metabolism 2020:154203. doi: 10.1016/j.metabol.2020.154203. 